\title{
Study on the Characteristics of Traction Forces Difference Asymmetric Steering Bogies
}

\author{
Yan Shi, Junxiong Hu, and Weihua Ma \\ Traction Power State Key Laboratory, Southwest Jiaotong University, Chengdu, China \\ Correspondence should be addressed to Weihua Ma; mwh@swjtu.cn
}

Received 14 June 2016; Accepted 4 October 2016

Academic Editor: Tai Thai

Copyright (C) 2016 Yan Shi et al. This is an open access article distributed under the Creative Commons Attribution License, which permits unrestricted use, distribution, and reproduction in any medium, provided the original work is properly cited.

\begin{abstract}
This article comes up with a new concept of applying the difference between traction forces on front and rear wheelsets to guiding control, as well as the design of a new type of structurally simple asymmetrical radial bogies, which lead to the proposition of traction forces difference-steering asymmetric radial bogies. The traction forces difference-steering asymmetric radial bogies are referred to as TFDA-bogies, in which the difference of longitudinal creep forces between front and rear wheels produces radial steering of both wheelsets. The concept of traction difference is incorporated into guiding control and bogie structure is also simplified in the form of asymmetrical radial bogies. Angle sensors are mounted to facilitate the change of electric currents of the front and rear traction motors to control the guiding mechanism so that wheelsets can adopt the radial position. With SIMPACK, the multibody dynamics analysis software, three whole vehicle models of TFDA-bogies, radial bogies, and conventional bogies are set up and comparative analyses are made on the lead wheel angle of attack, lead wheel lateral force, lead wheel friction power, and total vehicle friction power under idle running condition and traction condition, respectively. Results show that TFDA-bogies are radial bogies with simplified structure.
\end{abstract}

\section{Introduction}

One of the early well-known and successful applications of radial bogie technology to the vehicle bogies is Scheffel bogies [1], which were put into use in 1976 in South Africa. Due to the technological difficulty, the first DR-1 locomotive radial bogie [2] was not successfully developed until 1978. Totally dependent on wheel/rail creep force, self-steering bogies [3] have inferior steering performance to forced-steering bogies [4]. To solve the contradiction between traction and steering, actuated wheelset yaw bogies [5] come into being, wherein forced-steering bogies with driven motors, controlled radial bogies, electromechanical active steering, and stability control devices are among the successful applications at present. Forced-steering bogies with driven motors developed by German company AEG are operated through hydraulic cylinder to realize yaw adjustment of the wheelsets; the level length of hydraulic cylinder is adjusted to control each wheelset so that the latter can adopt the radial position [6]. Although this type of bogie is yet to be put into the practical application, it is a new idea of modern technology application due to its simple structure and steering function which is free from the impact of traction force. Actuation yaw bogies [7] have a working principle similar to forced-steering bogies: actuator mounted on the bogie frame is responsible for the moving of radial mechanism, so that wheelsets can adopt an approximately radial position in curves. In the 6th International Locomotive and Vehicle Bogie Congress in 2005, Bombardier Company introduced the dynamics performance and latest development of "MECHATRONICS" bogies, which have stability control and active electromechanical radial steering mechanism. Line tests show that this bogie can not only improve comfort and stability but also reduce noise and wear. However, its complex structure and high manufacturing cost inhibit its marketing promotion.

These actively controlled radial bogies are unanimously equipped with additional motors as actuators, thus this paper proposes a new design for asymmetric radial bogie guided and steered by traction forces difference of the front and rear wheelsets, which is simpler and more practicable compared with conventional bogies and traditional radial bogies, as demonstrated in the comparative study. 


\section{Guide Mechanism of Curve Negotiation}

During curve negotiation, vehicle is mainly guided by creep forces. In consideration of the vibration of steel rail at the wheel/rail contact points, the longitudinal creepage $\xi_{x-i}$, the lateral creepage $\xi_{y-i}$, and spin creepage $\xi_{\text {Spin }-i}$ are defined as follows $[8,9]$ :

$$
\begin{aligned}
& \xi_{x-i} \\
& =\frac{\text { Wheel longitudinal speed }- \text { Rail longitudinal speed }}{\text { Wheel nominal forward speed }} \\
& \xi_{y-i}=\frac{\text { Wheel lateral velocity }- \text { Rail lateral velocity }}{\text { Wheel nominal forward speed }} \\
& \xi_{\text {Spin-i }} \\
& =\frac{\text { Wheel angular velocity }- \text { Rail angular velocity }}{\text { Wheel nominal forward speed }}
\end{aligned}
$$

where $i=1,2$, representing the left and right contact points, respectively.

Assume that the steel rail is in a static state, neglecting the higher order infinitesimal terms of all kinematic amount; according to kinematic velocity synthesis method, (1) can be written alternatively as follows [10]:

$$
\begin{aligned}
\xi_{x-i} & =\left[1+(-1)^{i} \frac{r_{i}}{r_{0}}\right] \cos \left(\Psi_{w}\right)+\sin \left(\Psi_{w}\right) \frac{\dot{y}_{w}}{v} \\
+ & \frac{1}{r_{0}}\left\{\left[\Delta_{i}+(-1)^{i} l_{0}\right] \cos \left(\phi_{w}\right)-r_{0} \sin \left(\phi_{w}\right)\right\} \\
\cdot & {\left[\frac{r_{0} \dot{\Psi}_{w}}{v}\right]-(-1)^{i} \frac{l_{0}}{R}, } \\
\xi_{y-i} & =\left[-\sin \left(\Psi_{w}\right)+\frac{\dot{y}_{w}}{v} \cos \left(\Psi_{w}\right)\right] \cos \left[\phi_{w}-(-1)^{i} \delta_{i}\right] \\
+ & {\left[\frac{r_{i} \phi_{w}}{v}-\frac{\dot{\Delta}_{i}}{v}\right] \cos \left(\delta_{i}\right) } \\
+ & {\left[\left(l_{0}+(-1)^{i} \Delta_{i}\right) \frac{\phi_{w}}{v}+(-1)^{i} \frac{\dot{r}_{i}}{v}\right] \sin \left(\delta_{i}\right), } \\
+ & (-1)^{i} \frac{\cos \left(\delta_{i}\right)}{R}, \\
\xi_{\text {Spin }-i} & =\frac{1}{r_{0}} \cos \left[\delta_{i}-(-1)^{i} \phi_{w}\right] \frac{r_{0} \dot{\Psi}_{w}}{v}+(-1)^{i} \frac{\sin \left(\delta_{i}\right)}{r_{0}}
\end{aligned}
$$

where $\phi_{w}$ refers to roll angle of the wheelset; $\Psi_{w}$ is yaw angle of the wheelset; $y_{w}$ is the lateral displacement of the wheelset; $\delta_{i}$ is the wheel/rail contact angle; $\Delta_{i}$ is the displacement of wheel/rail contact point on wheel tread; $r_{i}$ is instantaneous wheelset rolling radius; $r_{0}$ is nominal wheelset rolling radius; $l_{0}$ is transverse distance between the central position of the wheelset and nominal wheelset rolling circle; $v$ is wheel forward speed; $R$ is curve radius.

Creep theory $[11,12]$ shows that as the angle of attack increases the lateral creep of wheelset increases. As a result,

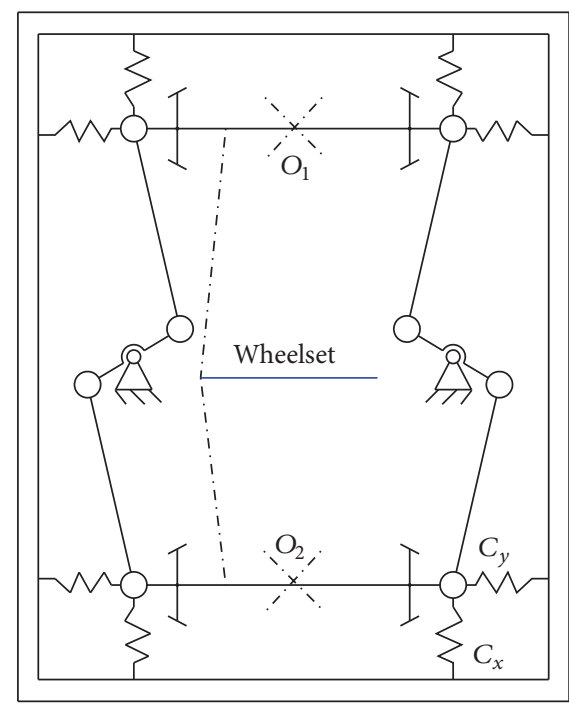

FIGURE 1: Diagram of radial bogie mechanism of locomotive E120.

the lateral creep forces between wheel and rail increase, which result in possible lateral displacement of the track and serious wheel/rail wear [13]; meanwhile, the longitudinal adhesion of the wheel decreases, which leads to reduction of gyrotraverse moment and degradation of adhesion performance. Thus, the angle of attack becomes a significant indicator to measure the curving performance of radial bogies. Reducing the level positioning stiffness of wheelset journal box helps to decrease the angle of attack, but the lateral stability of the bogie cannot be guaranteed.

\section{Structure and Mechanism of TFDA-Bogies}

Symmetrical radial bogie structure with " $Z$ "-shape rod is represented by the German E120 electric locomotive [14]. This radial bogie has symmetrical structure, with its front and rear axles rotating around axes $\mathrm{O}_{1}$ and $\mathrm{O}_{2}$, respectively, as well as equal moment arm for left and right wheels. As shown in Figure 1, during curve negotiation, the longitudinal creep forces of the left and right wheels generate a creep force moment. Under its effect, the front and rear axles rotate around axes $\mathrm{O}_{1}$ and $\mathrm{O}_{2}$, respectively, in the opposite direction, which compel the wheelset to take an approximately radial position in curves.

If the radial adjusting rod is only set at one end while the other end remains unchanged, the bogie would become asymmetrical. As shown in Figure 2(a), the centers of rotation $\mathrm{O}_{1}$ and $\mathrm{O}_{2}$ for the front and rear wheelsets move to the left side of journal box while " $\mathrm{Z}$ "-shape rod is located on its right side.

Under the effect of creep force moment, the right sides of the front and rear axles get close to each other or away from each other, while side of $\mathrm{O}_{1}$ and $\mathrm{O}_{2}$ remains the same, as shown in Figure 2(b). That is, increase the spacing between the outer wheels of the front and rear wheelsets, so that the wheelsets can adopt the radial position. It follows that the radial adjustment can be achieved as long as a " $Z$ "-shape rod is used to connect the front and rear wheelsets. 


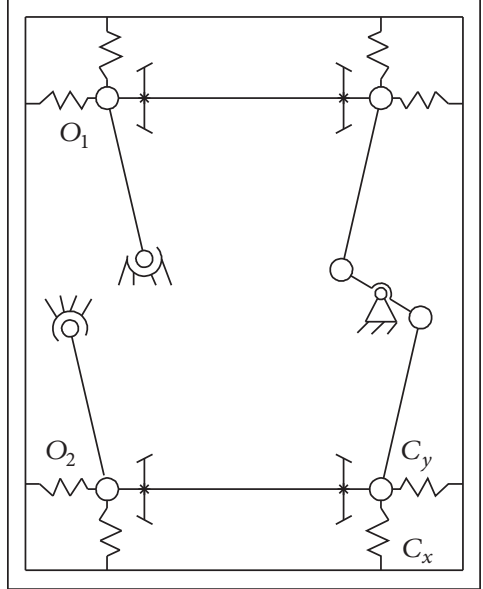

(a)

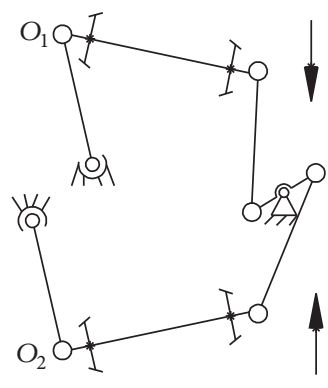

Right curve passing

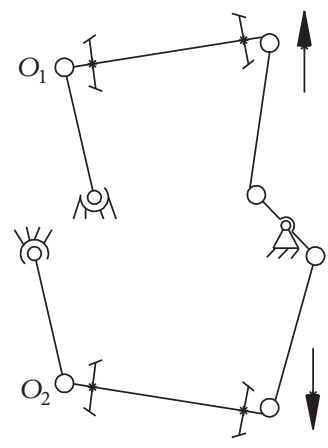

Left curve passing

(b)

FIGURE 2: Diagram of asymmetric radial bogie (a) mechanism and (b) curve negotiation mechanism.

Figure 3 shows the forces acting on the symmetrical radial mechanism [15]. Forces that the wheelsets are subjected to include wheel/rail creep force, creep force moment, wheel/rail normal contact force, forces of the primary suspension, and gravity force of wheelsets. Forces acting on the front and rear wheelsets are the same: $T$ is creep force, $T_{N}$ is normal contact force, and $F$ is the suspension force; $X$ represents the longitudinal direction, $L$ the left, and $R$ the right; $M$ is the moment and $W$ the gravity force of wheelset. For instance, $T_{x L}$ represents the longitudinal creep force of the left wheel of the front wheelset.

$A$ is spacing between journal boxes.

$B$ is spacing between the front wheel rolling circle and the journal box.

$C$ is spacing between the rear wheel rolling circle and the journal box.

An active control signal is mounted for the motors of the asymmetric radial bogie; then the curve directions can be detected and currents of the front and rear motors are accordingly adjusted so that the wheelsets can take the radial position. Such bogie is traction forces difference-steering asymmetric radial bogie (hereinafter referred to as TFDAbogie).

As shown in Figure $4, i_{F}$ and $i_{R}$ represent electric current of the front and rear motors, respectively. The abovementioned active control signal is, in effect, an angle sensor mounted on the car body, which gives a real-time monitoring to its bogie yaw $\alpha$ during curve negotiation. According to the detected bogie yaw $\alpha$, controller makes reasonable adjustment in the front and rear motor currents and thus generates a traction difference between the front and rear wheelsets, which exerts a moment of predetermined size and direction on the asymmetric radial mechanism so that the right ends of the front and rear wheelsets get close to or depart from each other.

The active control signal has many sources, which may include angle between before and after car body, angle

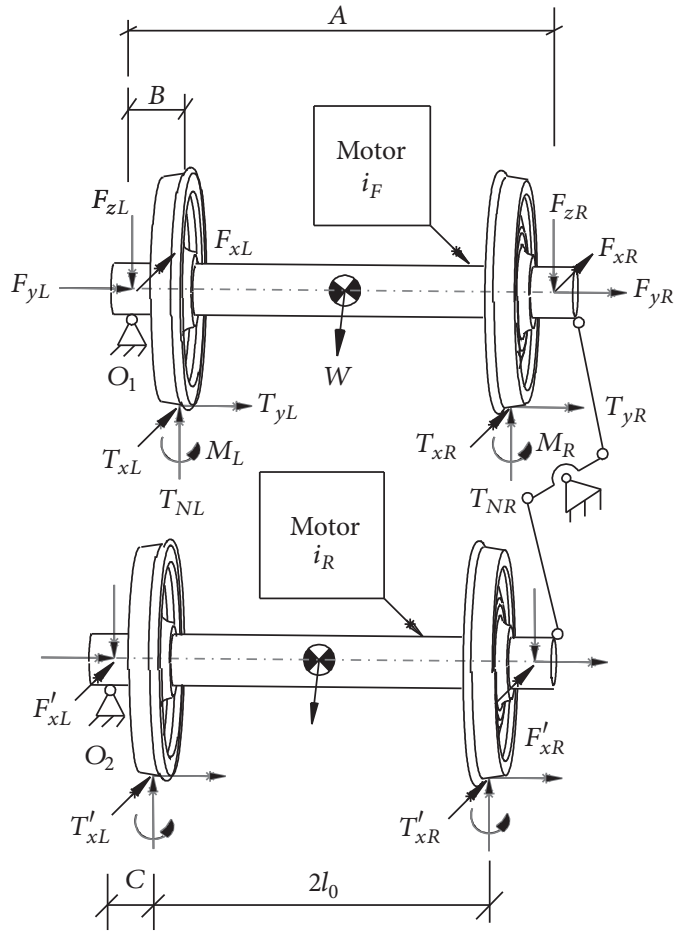

FIGURE 3: Force diagram of asymmetric radial bogie.

between the car body and radial frame, curve radius obtained from the lateral acceleration and vehicle velocity, the velocity of yaw angle, and vehicle speed. Some of these signals are relatively easy to measure, while some others are difficult to process. For example, some tilting signals, after being processed, can also be used for radial control $[16,17]$ but may lead to considerable error because of the need to measure the ultrahigh angle.

The above discussion applies to any type of radial bogies. However, the intermediate axle of triaxial bogies is not 


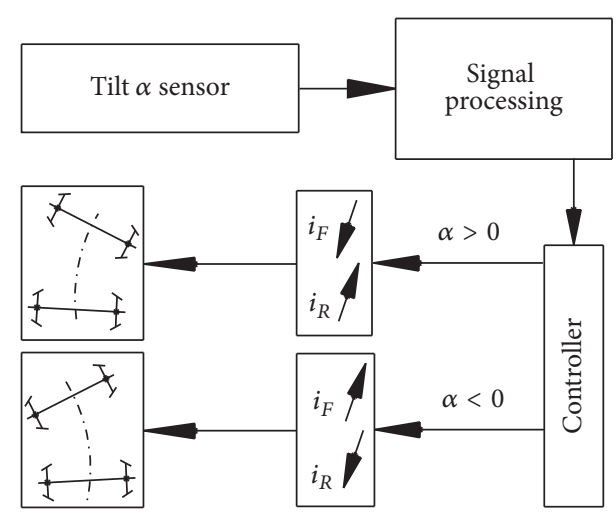

Figure 4: Diagram of the active control of TFDA-bogies.

TABLE 1: Common vehicle parameters.

\begin{tabular}{lc}
\hline Parameter & Value \\
\hline Bogie & \\
Body mass (kg) & 129125 \\
Length between bogie centres (m) & 17.5 \\
Length between wheelsets (m) & 1.7 \\
Wheel back gauge (m) & 1.493 \\
Nominal wheel radius (m) & 0.42 \\
Axle load (kg) & 25000 \\
Wheel profile & JM3 \\
Primary suspension (MN/m) & \\
Stiffness $x$-axis of TFDA-bogies & 20 \\
Stiffness $x$-axis of conventional bogies & 20 \\
Stiffness $x$-axis of radial bogies & 5 \\
Stiffness $y$-axis & 2.8 \\
Stiffness $z$-axis & 2.0 \\
Steering links stiffness (MN/m) & 20 \\
Vehicle velocity (m/s) & 13.88 \\
Track & \\
Rail profile & $\mathrm{UIC} 60$ \\
Gauge (m) & 1.435 \\
Rail cant & $1: 40$ \\
Length of curve (m) & $120 \mathrm{~m}$ \\
Friction coefficient & 0.3 \\
\hline
\end{tabular}

directly associated with the guide mechanism and thus is omitted in the figure.

\section{Vehicle and Bogie Model}

The vehicle models used are for three-axial bogie locomotives all with matching body, bogie frame, and wheelset dimensions and masses. The vehicle has a gross mass of 150 metric tons. Table 1 lists the key vehicle parameters.

With SIMPACK, the multibody dynamics software, dynamics models of TFDA-bogies, conventional bogies, and radial bogies are set up. Figure $5(\mathrm{a})$ is radial bogie and Figure 5(b) is TFDA-bogie, with only half the number of rods and joints of radial bogie in Figure 5(a).
JM3 is wear tread. Wheelset contact geometry is shown in Figure 6.

\section{Results}

5.1. Curving Performance Analysis. There are many indicators to measure the curving performance. Usually angle of attack of the wheelset, lead wheel lateral force, lead wheel friction power, and total vehicle friction power can determine whether a bogie has good or poor curving performance. With SIMPACK, wheel/rail creep force is calculated according to the Kalker's nonlinear creep theory, while the relationship between wheel/rail contact force and creepage is based on FASTSIM algorithm, the simplified theory of Kalker [18, 19].

Wheel wear power $P$ reflects the wear of wheel/rail tread, which can be calculated according to the following formula [20]:

$$
P=v \cdot\left(T_{x} \xi_{x}+T_{y} \xi_{y}+T_{\text {Spin }} \xi_{\text {Spin }}\right)
$$

where $T_{x}$ is longitudinal creep force; $T_{y}$ is lateral creep force; $T_{\text {Spin }}$ is creep torque.

The wear power of the whole vehicle is determined by the algebraic sum of wear power of all wheels and reflects the wheel/rail wear level of the vehicle.

When the traction $T$ on each wheelset is set at 0 , it is idle running condition; otherwise it is traction condition. Traction forces of $150 \mathrm{kN}$ are applied on locomotives with three different types of bogies, respectively. While driving in a straight line, the $150 \mathrm{kN}$ traction force is evenly allocated to the 6 wheelsets and thus traction force acting on each wheelset is $25 \mathrm{kN}$. When each bogie is about to negotiate the curve, TFDA-bogies adopt the following control strategy: when the right turn signal is emitted from the angle sensor, keep the traction on the intermediate wheelsets 2 and 5 unchanged, cut off the motor current $i_{F}$ of wheelsets 1 and 4 , and thus bring their traction down from $25 \mathrm{kN}$ to 0 . Meanwhile, increase the motor current $i_{R}$ of wheelsets 3 and 6 , and thus raise their traction from $25 \mathrm{kN}$ to $50 \mathrm{kN}$, so the traction difference of the front and rear wheelsets $\Delta T 50 \mathrm{kN}$ is generated.

When each bogie negotiates $R=300 \mathrm{~m}, R=400 \mathrm{~m}, R=$ $500 \mathrm{~m}, R=600 \mathrm{~m}, R=800 \mathrm{~m}, R=1000 \mathrm{~m}, R=1200 \mathrm{~m}$, and $R=$ $1600 \mathrm{~m}$ curves, respectively, indicators like lead wheel angle of attack, lead wheel lateral force, and wear power of the whole vehicle are obtained, all of which are shown in Figure $7 ; T$ represents tractive force acting on each wheelset (similarly hereinafter).

As shown in Figure 7, lead wheel angle of attack of the conventional bogies reaches the maximum during curve negotiation with tractive force exerted. When the curve radius is above $800 \mathrm{~m}$, radial bogies lose guiding function. Under idle running condition, angle of attack of TFDAbogies is close to that of the conventional bogies; the guiding force of TFDA-bogies is inferior, in which, guiding force is referred to the outer side wheel/rail lateral force of the first wheelset on the curved track and the sign of " \pm " is referred to different direction; the lead wheel wear power of TFDA-bogies is similar to that of conventional bogies 


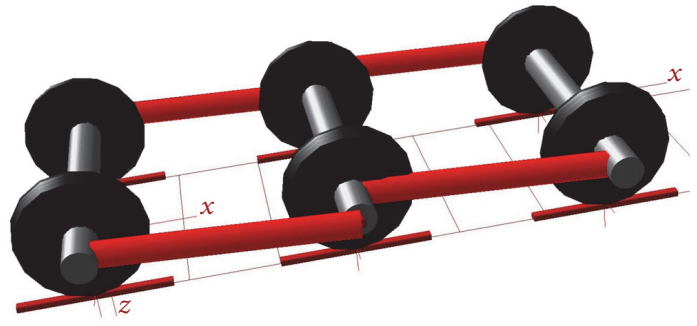

(a)

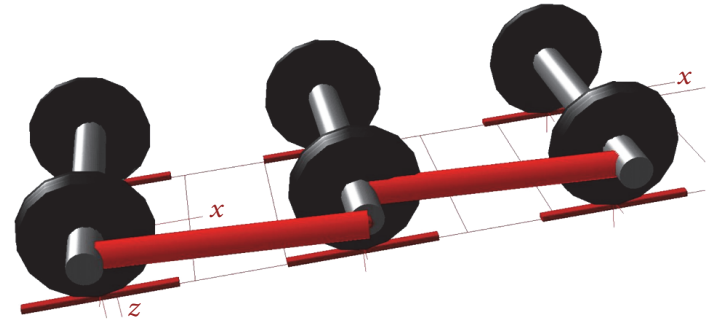

(b)

Figure 5: (a) Radial bogie and (b) TFDA-bogie.

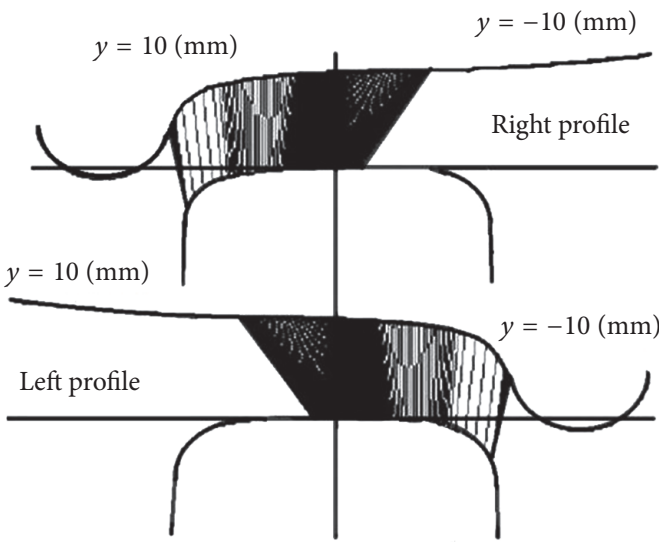

Nominal wheel radius $420 \mathrm{~mm}$

(a)

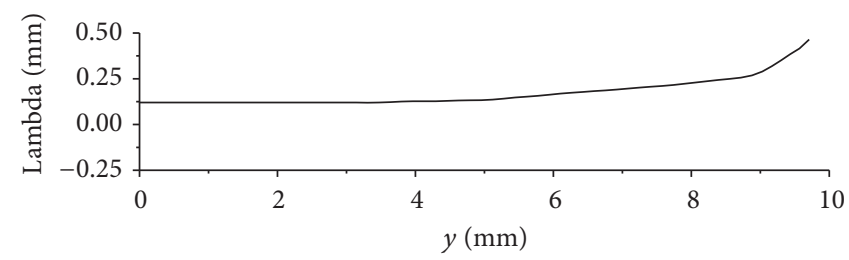

(b)

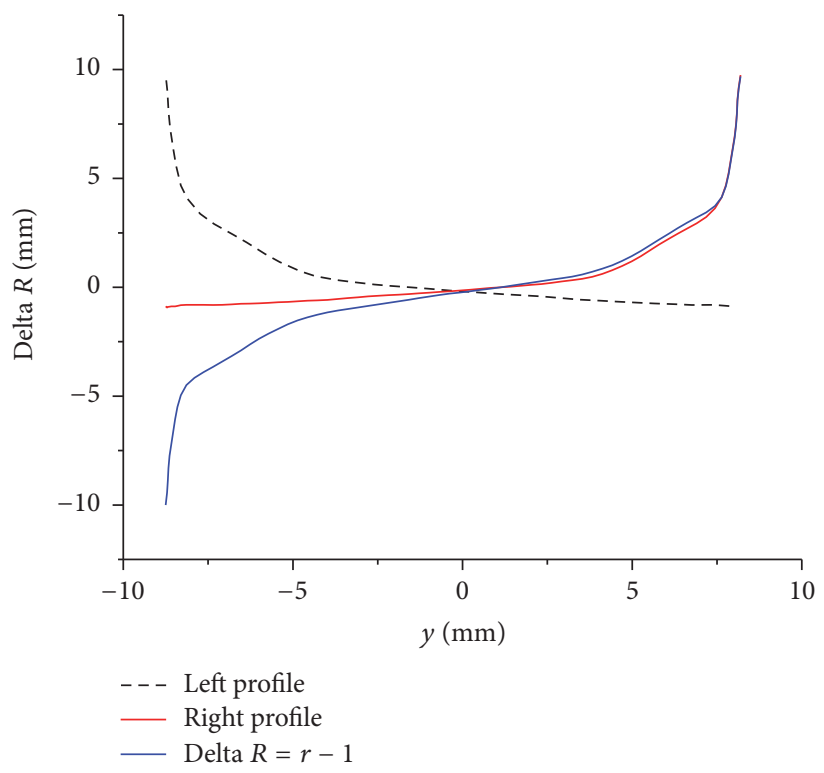

(c)

FIGURE 6: Wheelsets contact geometry: (a) contact connections; (b) equivalent conicity; (c) wheel diameter difference.

while the whole vehicle wear power of TFDA-bogies is inferior. Under traction condition, the overall performance of TFDA-bogies is superior to conventional bogies, as traction is an important factor affecting the whole vehicle wear power. Due to the fourfold difference in longitudinal positioning stiffness, dynamics indicators of TFDA-bogies are not as good as radial bogies. The longitudinal positioning stiffness of TFDA-bogies needs reducing for the sake of further analysis.

5.2. Effect of Front and Rear Wheelsets Traction Difference on Guiding Performance. During curve negotiation with 


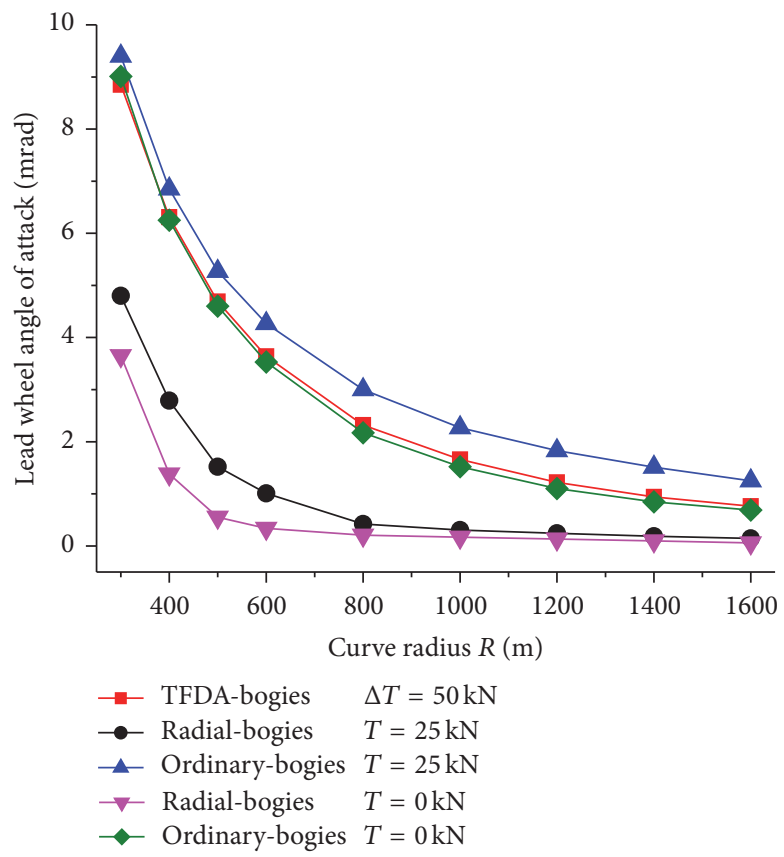

(a)

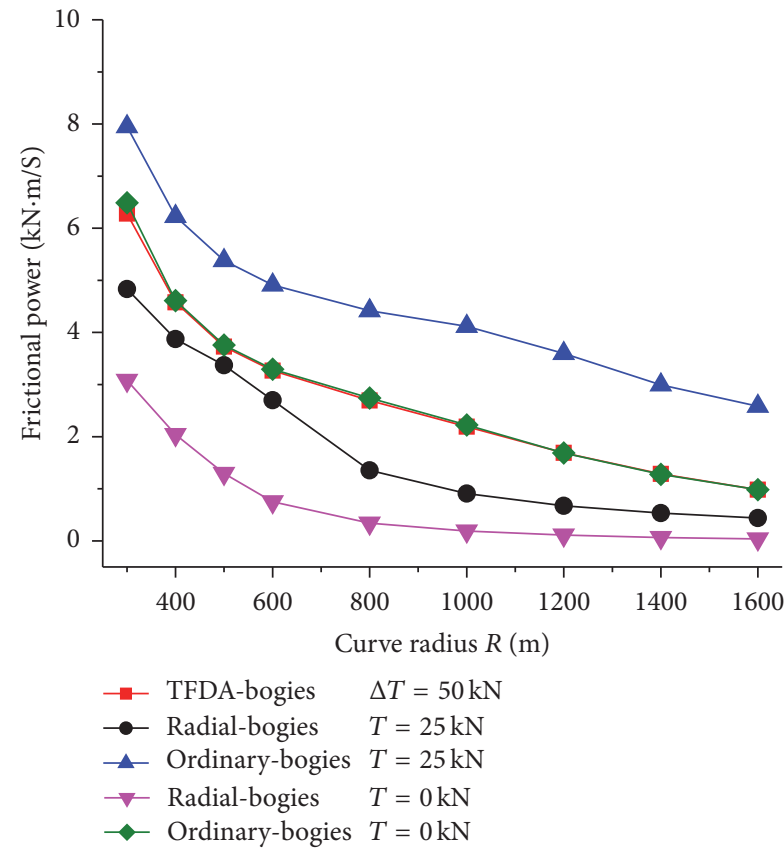

(c)

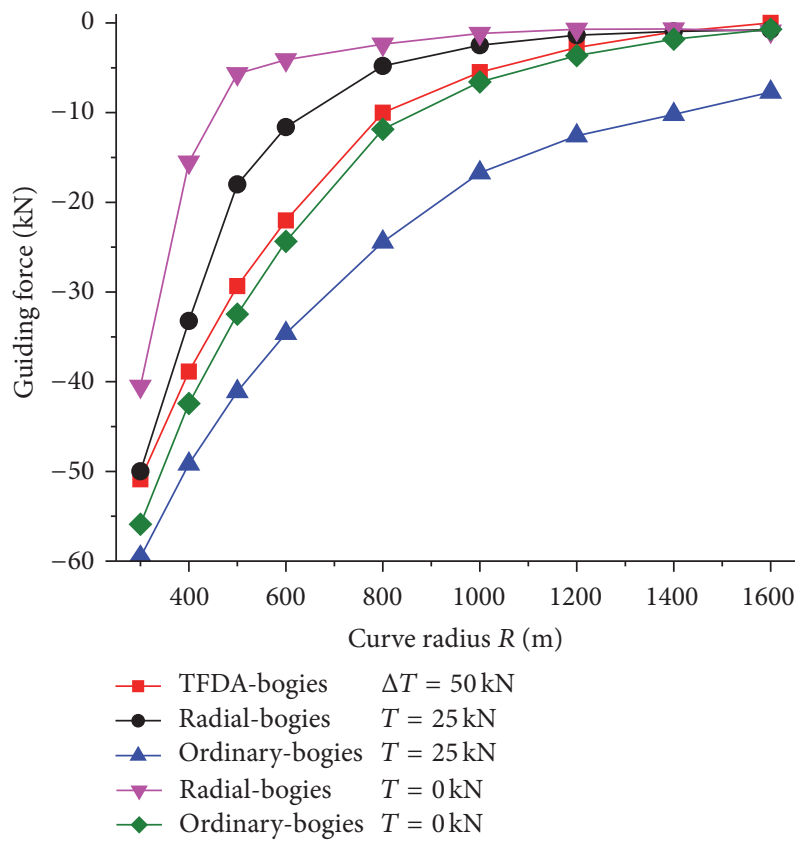

(b)

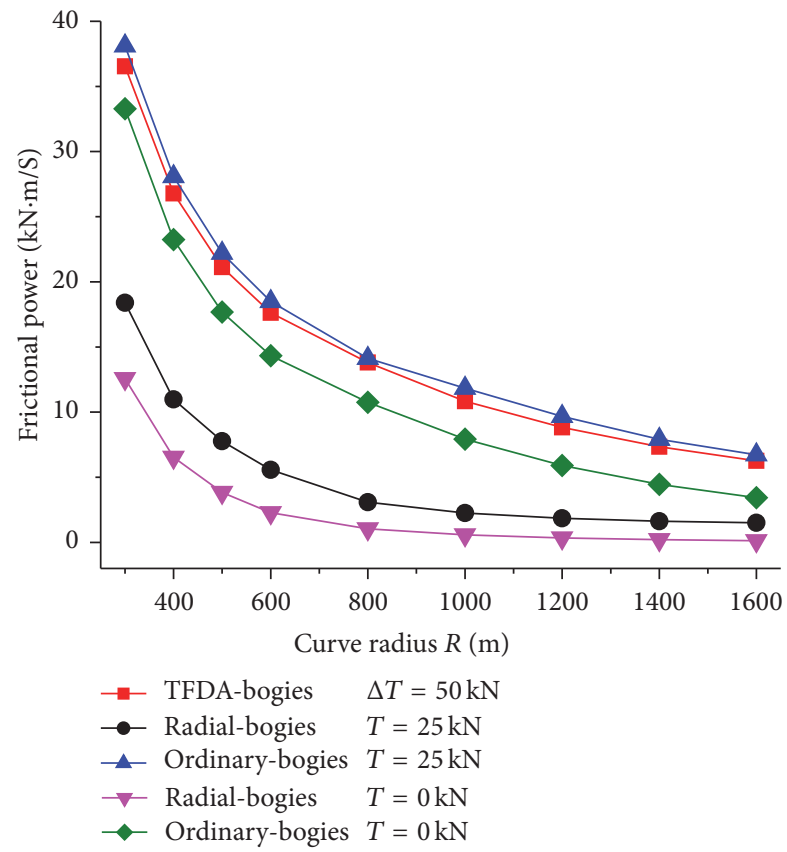

(d)

Figure 7: Each bogie performance comparison, (a) lead wheel angle of attack, (b) lead wheel lateral force, (c) lead wheel friction power, and (d) total vehicle friction power.

tractive force exerted, traction changes the size and direction of the wheel/rail longitudinal creep forces and lateral creep forces, thereby reducing self-steering function of bogies. In order to analyse the beneficial effect of traction difference on the guiding performance, dynamics performances of TFDAbogies are examined when negotiating $R=600 \mathrm{~m}$ radius curve with superelevation at $50 \mathrm{~mm}$.
The total tractive forces acting on locomotive with TFDAbogies are set at $60 \mathrm{kN}, 120 \mathrm{kN}$, and $180 \mathrm{kN}$, respectively, and accordingly tractive force acting on each wheelset is evenly allocated at $10 \mathrm{kN}, 20 \mathrm{kN}$, and $30 \mathrm{kN}$, when the tractive force difference strategy is not adopted. When the strategy is applied, keep the traction on the intermediate wheelsets 2 and 5 unchanged, bring the traction on the front wheelsets 1 and 4 


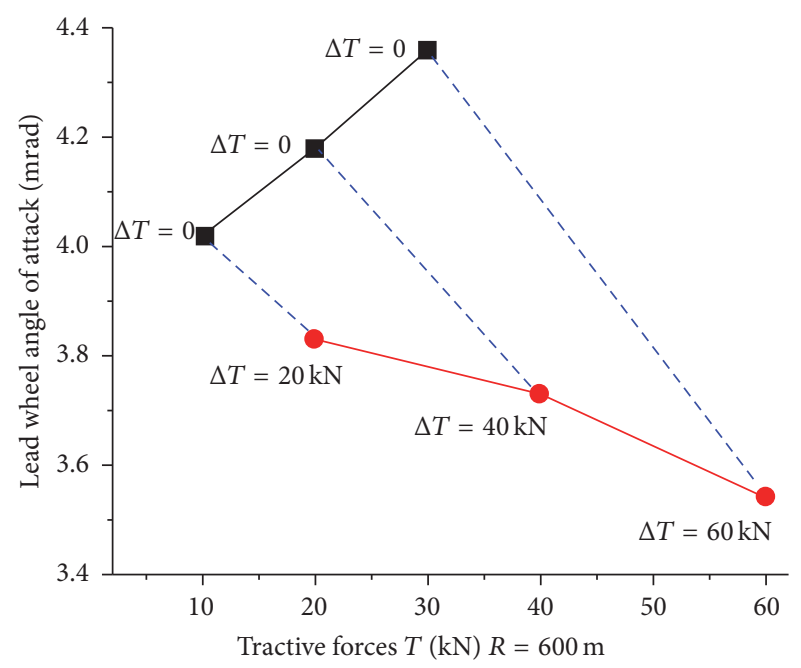

(a)

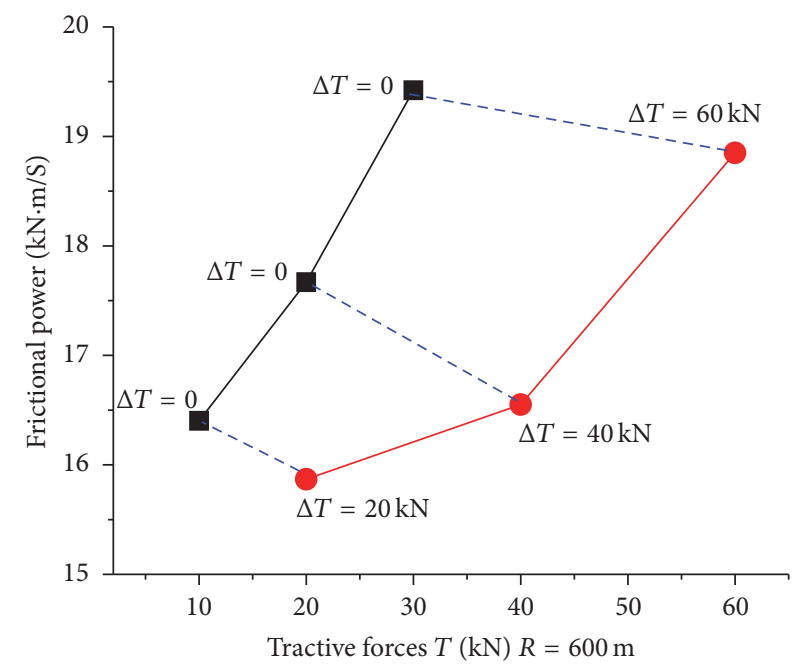

(b)

Figure 8: $\Delta T$ influence on guiding performance, (a) $\Delta T$-dependence changing curve of lead wheel angle of attack and (b) $\Delta T$-dependence changing curve of total vehicle friction power.

down to 0 , and raise the traction on the rear wheelsets 3 and $6 \mathrm{up}$; therefore, the traction difference $\Delta T$ of each front and rear wheelsets are $20 \mathrm{kN}, 40 \mathrm{kN}$, and $60 \mathrm{kN}$, respectively. The results of calculation are indicated in Figure 8.

Tractive forces have significantly improved the yaw angle. When the total tractions are the same, lead wheel angle of attack decreases at most by $18.8 \%$ and the whole vehicle wear power decreases at most by $6.3 \%$. When tractive force acting on each wheelset is the same, lead wheel angle of attack and the whole vehicle wear power increase as total traction increases; while traction difference $\Delta T$ is introduced, lead wheel angle of attack is effectively reduced and even keeps the down trend as total traction increases. Although the whole vehicle wear power increases as total traction increases, its growth can be slowed down through the control of traction difference $\Delta T$. For instance, when total traction is $120 \mathrm{kN}$ and the corresponding traction difference is $40 \mathrm{kN}$, the whole vehicle wear power achieves the maximum reduction of $6 \%$.

5.3. Effect of Longitudinal Axle Stiffness. When the longitudinal axle stiffness $C_{x}$ of TFDA-bogies is reduced from $20 \mathrm{MN} / \mathrm{m}$ to $10 \mathrm{MN} / \mathrm{m}$ and $5 \mathrm{MN} / \mathrm{m}$, other parameters unchanged, under the condition of total traction at $120 \mathrm{kN}$ and the corresponding traction difference at $40 \mathrm{kN}$, the curving performances of TFDA-bogies and radial bogies when negotiating a curved track of $400 \mathrm{~m}, 600 \mathrm{~m}, 800 \mathrm{~m}$, $1000 \mathrm{~m}, 1200 \mathrm{~m}$ and $1600 \mathrm{~m}$, respectively, are compared and the results are shown in Figure 9.

Lead wheel angle of attack and lead wheel wear power of TFDA-bogies decrease as longitudinal axle stiffness $C_{x}$ decreases. With same $C_{x}$, lead wheel angle of attack of TFDAbogies is similar to that of radial bogies under traction condition; guiding force of TFDA-bogies when negotiating the curve of $600 \mathrm{~m}$ to $1200 \mathrm{~m}$ is similar to that of radial bogies under idle running condition; lead wheel wear power of TFDA-bogies falls in between that of radial bogies under idle running condition and traction condition, while retaining similarity with that of radial bogies under idle running condition when curve radius is above $800 \mathrm{~m}$; and the whole vehicle wear power of TFDA-bogies is all the way inferior to that of radial bogies under traction condition.

5.4. TFDA-Bogies Symmetry Analysis. S-shape curves are studied when TFDA-bogies negotiate the curve of $400 \mathrm{~m}$, $600 \mathrm{~m}, 800 \mathrm{~m}, 1000 \mathrm{~m}, 1200 \mathrm{~m}$, and $1600 \mathrm{~m}$, respectively, with $50 \mathrm{kN}$ traction difference applied, and the results are shown in Figure 10.

Lead wheel angle of attack and the whole vehicle wear power of TFDA-bogies have better symmetrical characteristics while the guiding force and lead wheel wear power are symmetrically inferior, with corresponding average difference at $8.0 \mathrm{kN}$ and $0.9 \mathrm{kN} \cdot \mathrm{m} / \mathrm{s}$. Considering the wear indicator, TFDA-bogies have comparatively weak performances when negotiating the right curve. However, as all the abovementioned analysis involves right curve, the comparative analysis between TFDA-bogies and other bogies are accordingly reliable.

\section{Conclusion and Outlook}

Studies have been carried out on the curving performances of three different bogies, of which TFDA-bogies, as a new type of radial bogie negating curves by using traction difference, has never been researched before. Studies show that certain performance indicators of TFDA-bogies can reach the level of radial bogies under idle running condition, which develops a vision for future study. Thus, conclusions are made and outlook is put forward based on the present research level.

(1) TFDA-bogies mechanism is structurally simple, in particular, for electrical engineers, from the sensor to the motor control. Active control signal sources are readily available, such as the angle between the car body and bogie 


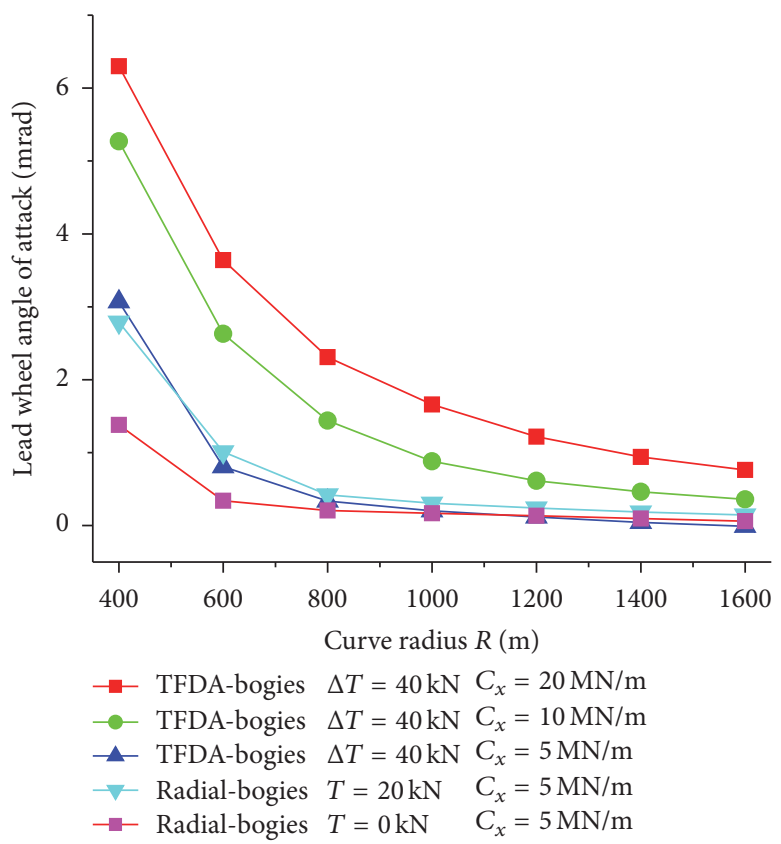

(a)

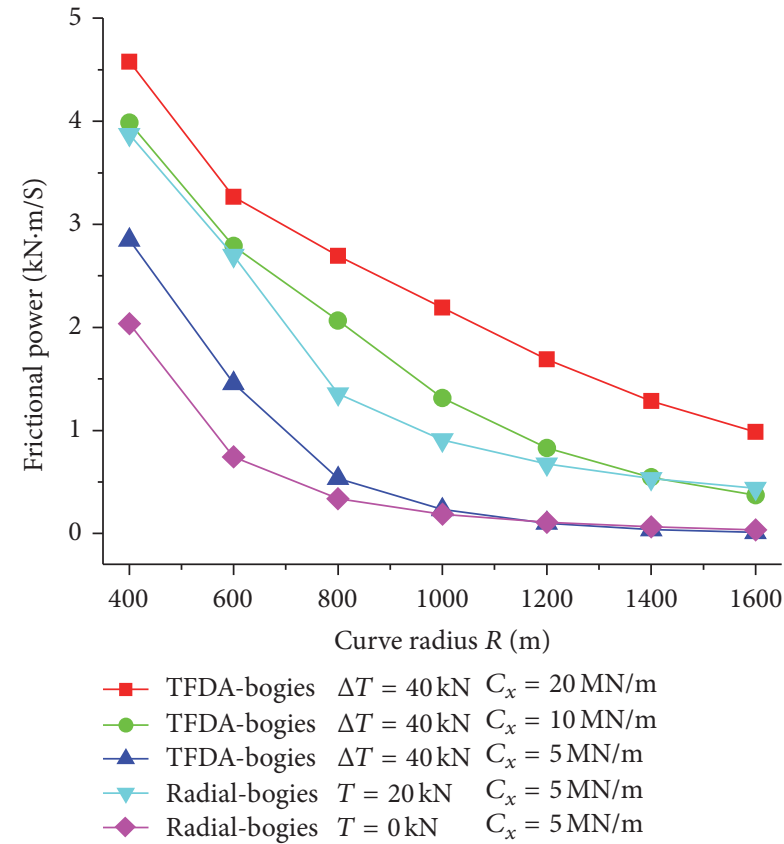

(c)

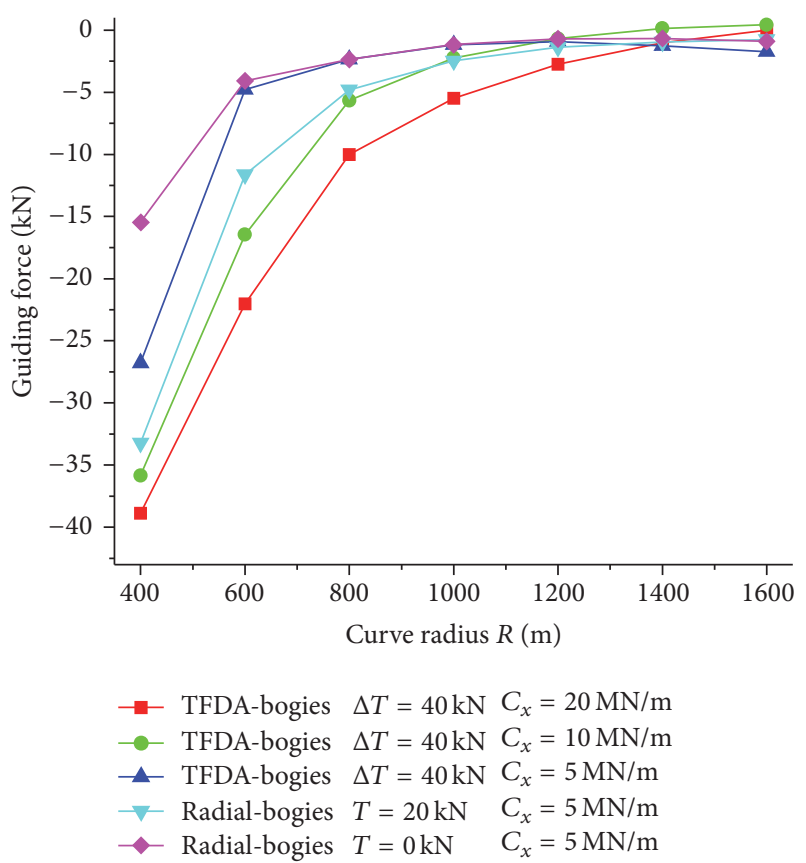

(b)

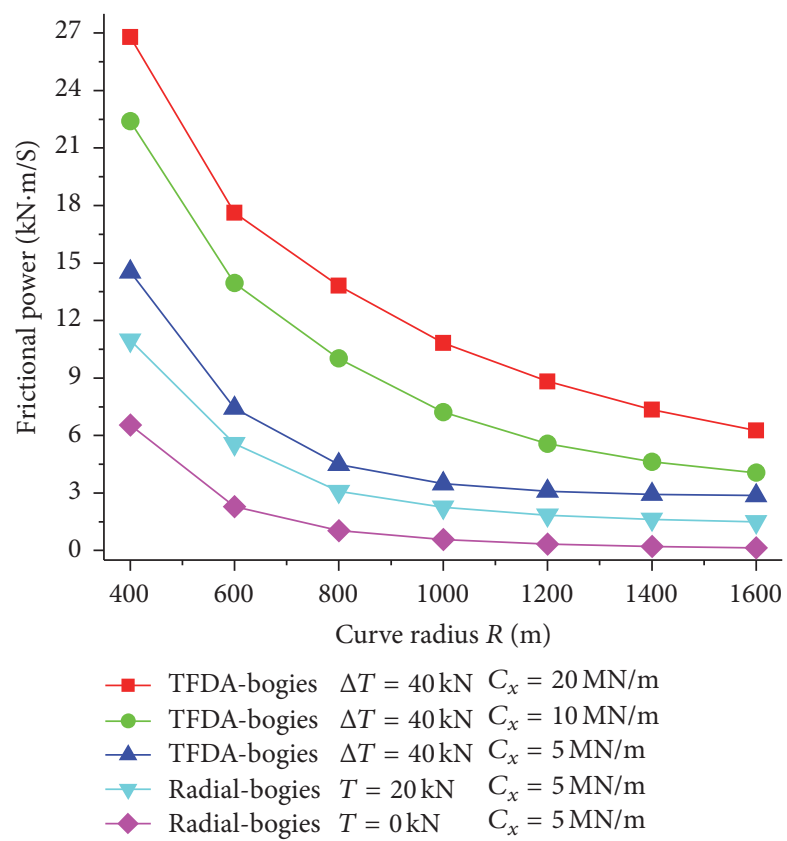

(d)

FIGURE 9: Each bogie performance comparison, (a) lead wheel angle of attack, (b) lead wheel lateral force, (c) lead wheel friction power, and (d) total vehicle friction power.

frame, which is relatively easy to process and has a strong antiinterference performance.

(2) Under the same condition, the curving performance of TFDA-bogies is superior to conventional bogies; while compared with radial bogies, both have their own merits and demerits.

(3) The curving performance of TFDA-bogies is yet to be improved via in-depth research; for instance, can the whole vehicle wear power be elevated to the level of radial bogies by adjusting the parameters of TFDA-bogies? How to minimize the difference of lead wheel friction power on the right and left curves?

(4) Asymmetrical radial bogies are structurally simplified radial bogies, which serve as the simplest radial mechanism for traction difference applied. Can the concept of traction difference be separated from the radial mechanism? To this 


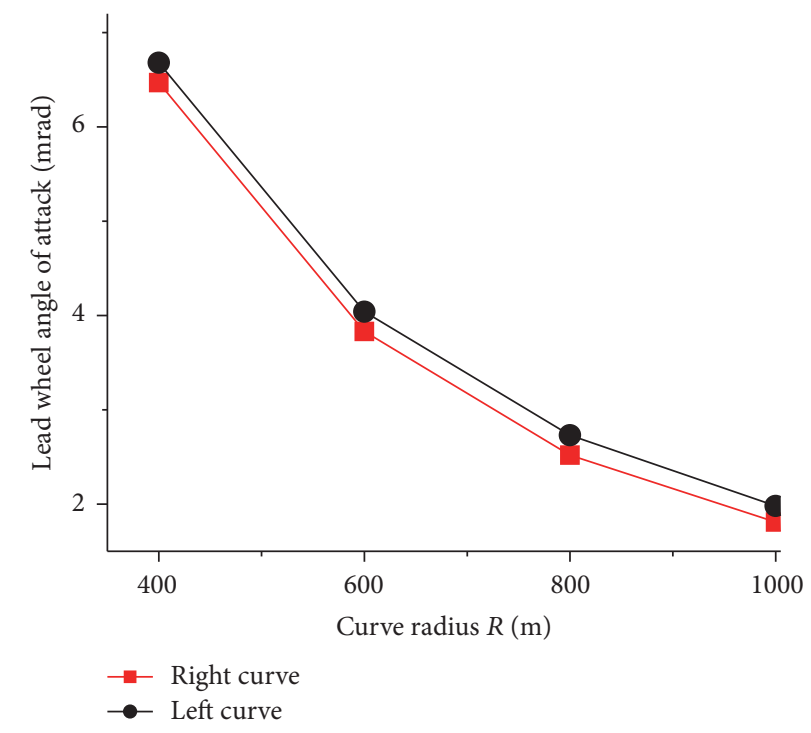

(a)

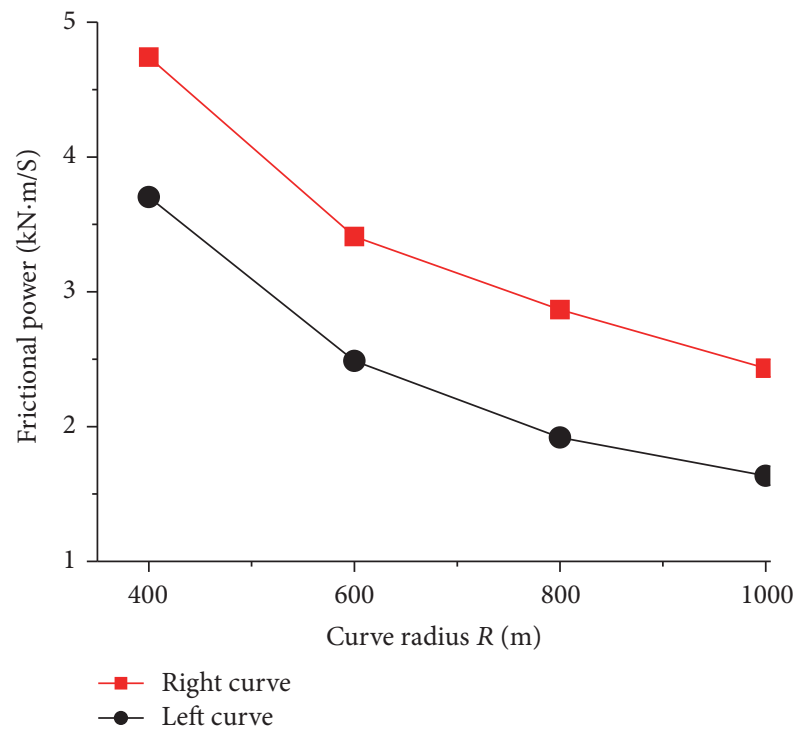

(c)

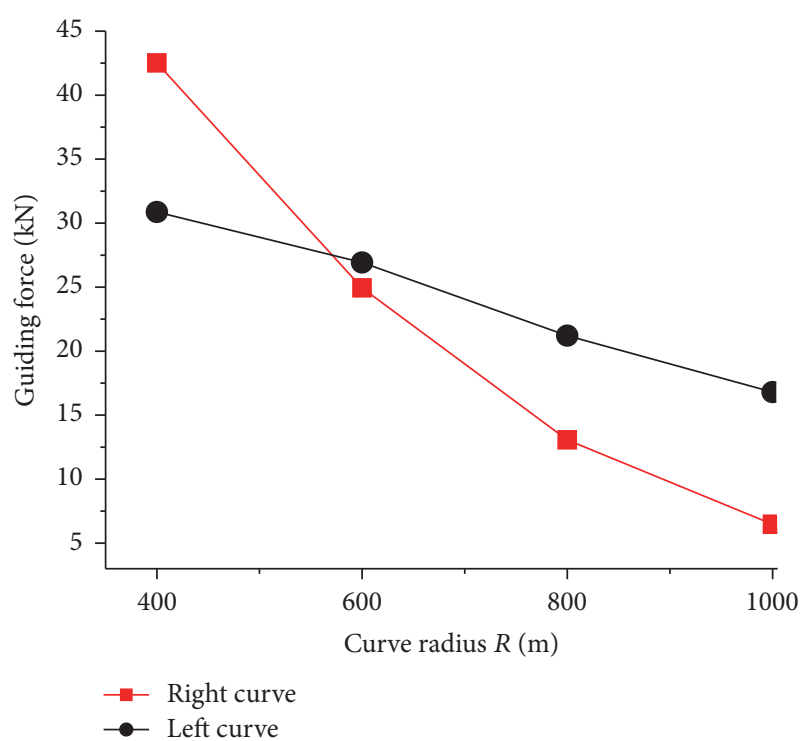

(b)

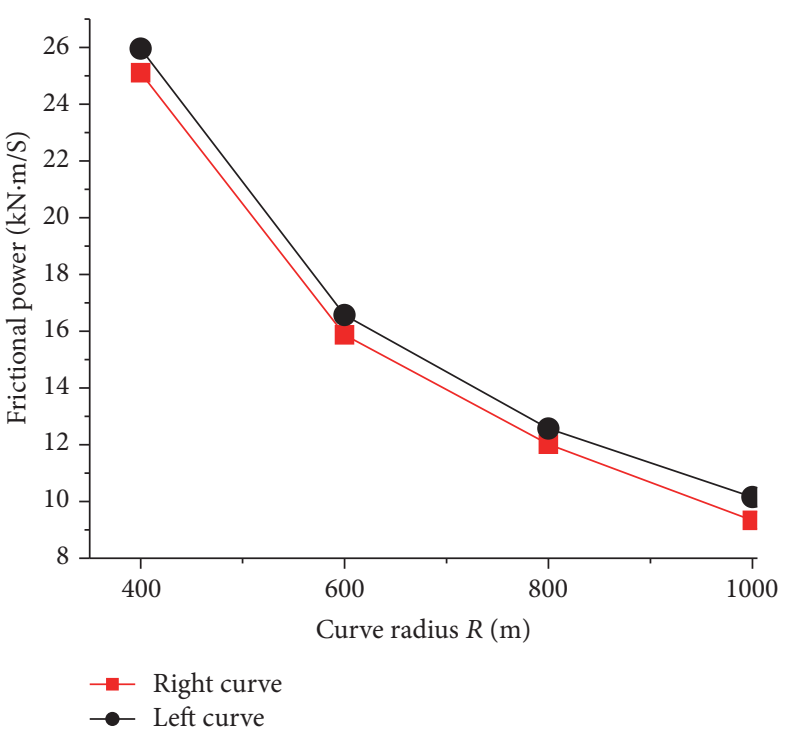

(d)

FIGURE 10: TFDA-bogies symmetry analysis, (a) lead wheel angle of attack, (b) lead wheel lateral force, (c) lead wheel friction power, and (d) total vehicle friction power.

end, what kind of role does the traction gear box play? Questions of this regard are yet to be solved in the future studies.

\section{Competing Interests}

The authors declared no potential competing interests with respect to the research, authorship, and/or publication of this article.

\section{Acknowledgments}

The work is supported by the independent Research Project of Traction Power State Key Laboratory (no. 2016TPL-T10) and the National Natural Science Foundation of China (Grant no. 51575458).

\section{References}

[1] H. Scheffel, "Experience gained by South african railways with diagonally stabilised (CROSS-ANCHOR) bogies having selfsteering wheelsets," in Proceedings of the Heavy Haul Railways Conference, Perth, Western Australia, 1978.

[2] H. A. List and G. Venn-Brown, Design and Development of a Retrofittable Steering Assembly for Australian Conditions, Institution of Engineers, Australia, 1985.

[3] M. Ahmadian and W. Huang, "A qualitative analysis of the dynamics of self-steering locomotive trucks," Vehicle System Dynamics, vol. 37, no. 2, pp. 85-127, 2002. 
[4] R. E. Smith and J. Kalousek, "A design methodology for wheel and rail profiles for use on steered railway vehicles," Wear, vol. 144, no. 1-2, pp. 329-342, 1991.

[5] R. M. Goodall, "Control engineering challengs for railway trains of the future," Measurement and Control, vol. 44, no. 1, pp. 16-24, 2011.

[6] F. Braghin, S. Bruni, and F. Resta, "Active yaw damper for the improvement of railway vehicle stability and curving performances: simulations and experimental results," Vehicle System Dynamics, vol. 44, no. 11, pp. 857-869, 2006.

[7] N. Miyajima, A. Matsumoto, Y. Suda et al., "Multi-body dynamics simulation and bogie structure evaluation for activebogie steering truck," in Proceedings of the ASME International Mechanical Engineering Congress and Exposition (IMECE '07), pp. 459-465, November 2007.

[8] M. Ciavarella and J. Barber, "Influence of longitudinal creepage and wheel inertia on short-pitch corrugation:a resonance-free mechanism to explain the roaring rail phenomenon," Proceedings of the Institution of Mechanical Engineers, Part J: Journal of Engineering Tribology, vol. 222, no. 3, pp. 171-181, 2008.

[9] J. J. Kalker, Three-Dimensional Elastic Bodies in Rolling Contact, vol. 2, Kluwer Academic Publishers, Dordrecht, The Netherlands, 1990.

[10] W. Zhai, J. Gao, P. Liu, and K. Wang, "Reducing rail side wear on heavy-haul railway curves based on wheel-rail dynamic interaction," Vehicle System Dynamics, vol. 52, no. 1, pp. 440454, 2014.

[11] O. Polach, "Creep forces in simulations of traction vehicles running on adhesion limit," Wear, vol. 258, no. 7-8, pp. 992$1000,2005$.

[12] J. Santamaria, E. G. Vadillo, and J. Gomez, "Influence of creep forces on the risk of derailment of railway vehicles," Vehicle System Dynamics, vol. 47, no. 6, pp. 721-752, 2009.

[13] S. Yamashita, A. Sakamaki, and H. Sugiyama, "Creep force characteristics of wheel/rail contact under friction control," in Proceedings of the International Mechanical Engineering Congress and Exposition (ASME '11), pp. 375-379, Denver, Colo, USA, November 2011.

[14] A. Schaefer-Enkeler, "Drehgestelle mit radial einstellbaren radsaetzen fuer triebfahrzeuge," Zeitschrift für Eisenbahnwesen und Verkehrstechnik, vol. 116, pp. 44-48, 1992.

[15] S. A. Simson and C. Cole, "Idealized steering for hauling locomotives," Proceedings of the Institution of Mechanical Engineers, Part F: Journal of Rail and Rapid Transit, vol. 221, no. 2, pp. 227236, 2007.

[16] C. P. Ward, P. F. Weston, E. J. C. Stewart et al., "Condition monitoring opportunities using vehicle-based sensors," Proceedings of the Institution of Mechanical Engineers, Part F: Journal of Rail and Rapid Transit, vol. 225, no. 2, pp. 202-218, 2011.

[17] R. M. Goodall, "Control for railways-active suspensions and other opportunities," in Proceedings of the 19th Mediterranean Conference on Control and Automation (MED '11), pp. 639-643, June 2011.

[18] A. Alonso, J. G. Giménez, and L. M. Martín, "Spin moment calculation and its importance in railway dynamics," Proceedings of the Institution of Mechanical Engineers, Part F: Journal of Rail and Rapid Transit, vol. 223, no. 5, pp. 453-460, 2009.

[19] J. J. Kalker, Three-Dimensional Elastic Bodies in Rolling Contact, vol. 2, Springer, Dordrecht, The Netherlands, 1990.

[20] S. Yan-Swjtu, Z. Wu, W. Ma, and L. Zong, "Comparison of curving performance among bogies of different types," Journal of the Balkan Tribological Association, vol. 22, no. 2, pp. 1175$1183,2016$. 


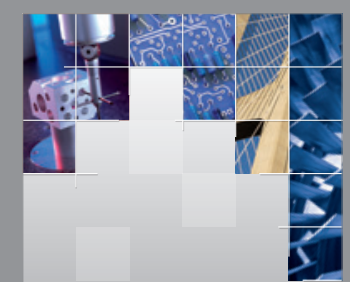

\section{Enfincering}
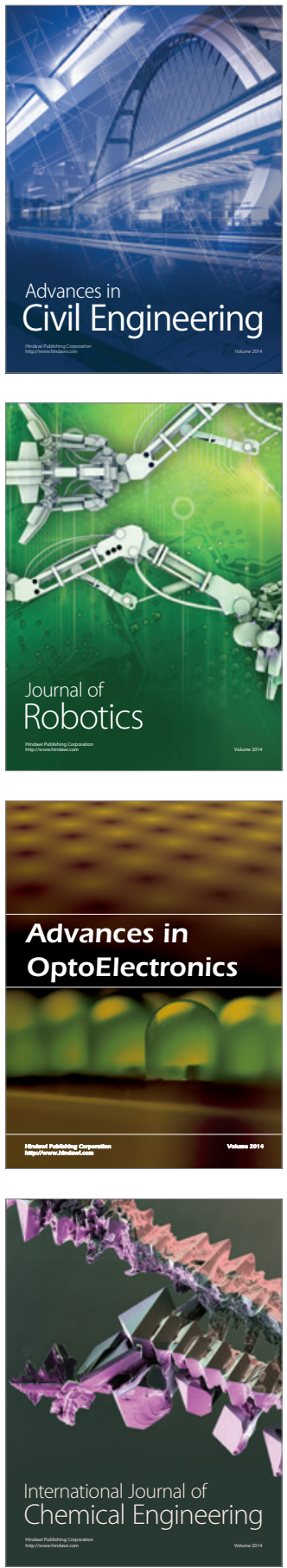

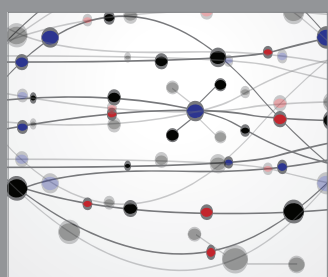

The Scientific World Journal

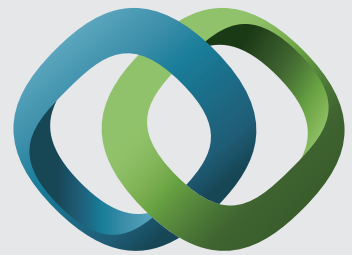

\section{Hindawi}

Submit your manuscripts at

http://www.hindawi.com
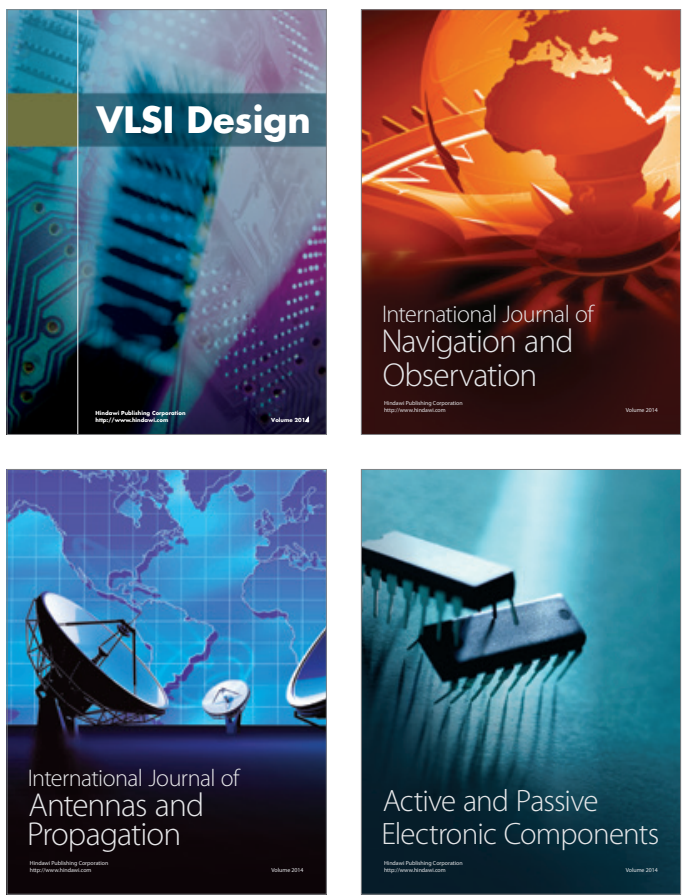
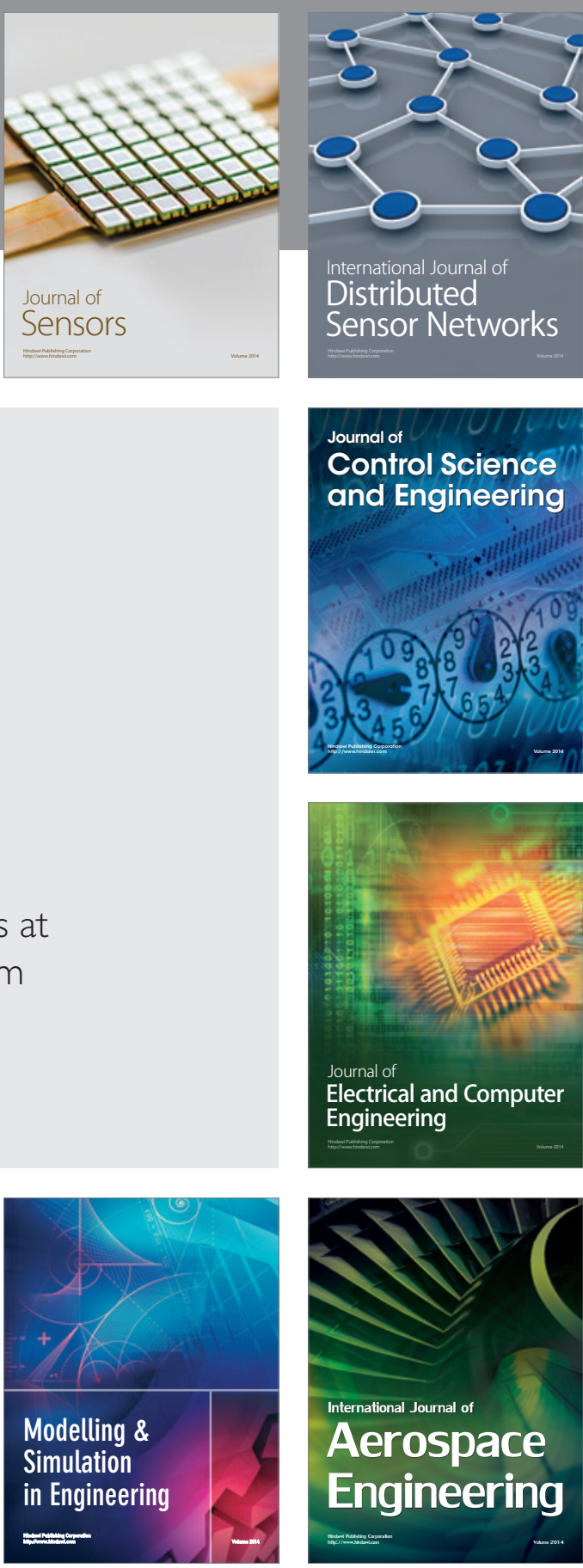

International Journal of

Distributed

Sensor Networks

Journal of

Control Science

and Engineering
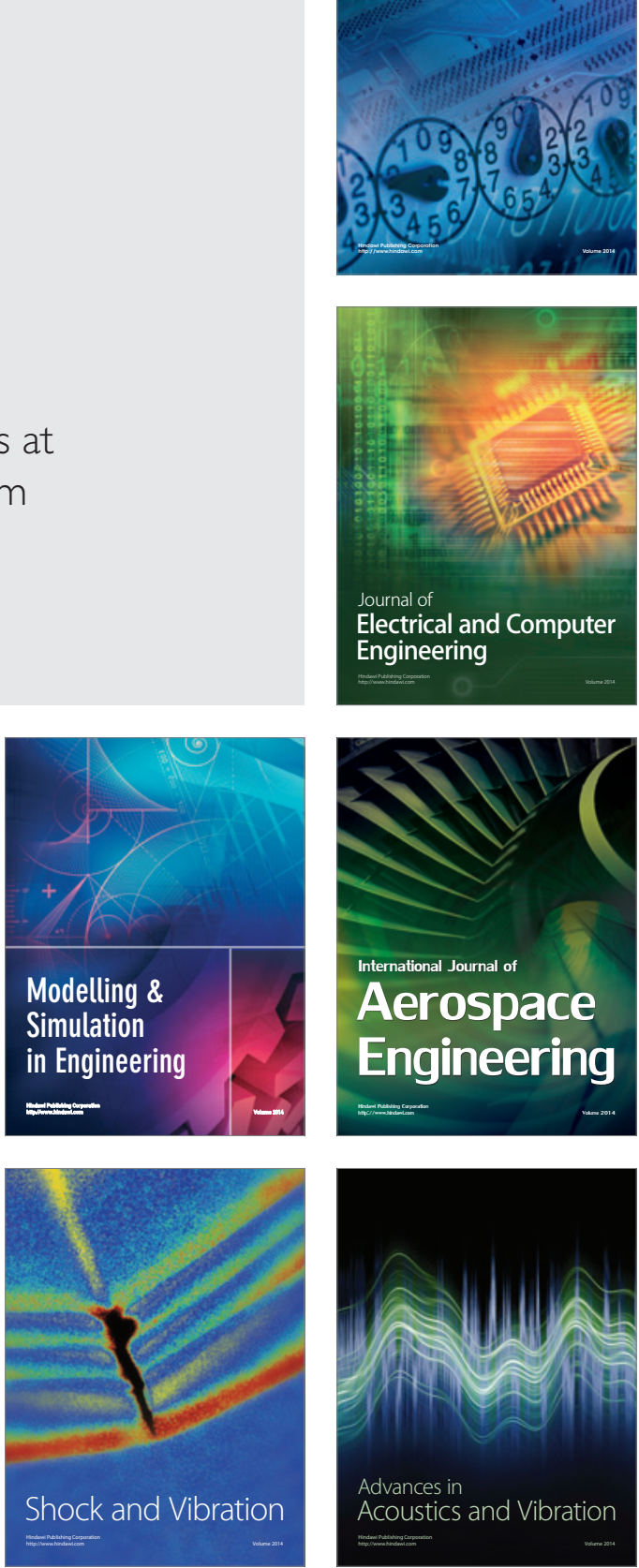